\title{
Analytical Method Development and Validation of Related Substances in Etoricoxib (API) by Using RP-HPLC
}

\author{
K. SUSMETHA, K. S. NATARAJ*, A.S. RAO and B. D. M. S. P. SAI \\ Shri Vishnu College of Pharmacy, Vishnupur, Bhimavaram-534202, A.P., India \\ kalakondan@yahoo.com
}

Received 4 August 2018 / Accepted 7 September 2018

\begin{abstract}
This article describes the development and validation of related substances in Etoricoxib by using RP-HPLC and degradation products generated from the forced degradation studies. Etoricoxib was subjected to stress conditions such as acid, alkaline, oxidative, thermal and photo degradation. It was found to be stable in all these conditions except in oxidation environment. Successful separation of drugs was achieved on Inertsil ODS-3V, $(4.6 \times 250 \mathrm{~mm}, 5 \mu \mathrm{m}) \mathrm{C}_{18}$ at $25^{\circ} \mathrm{C}$. Gradient elution at a flow rate of $1.0 \mathrm{~mL} / \mathrm{min}$. The mobile phase consisted of mixture of Buffer: Acetonitrile Buffer $\left(0.01 \mathrm{M} \mathrm{KH}_{2} \mathrm{PO}_{4}\right)$ in the ratio of $90: 10(\mathrm{v} / \mathrm{v})$ respectively and UV detection wavelength was $238 \mathrm{~nm}$. The $\mathrm{R}_{\mathrm{t}}$ value of Impurity-05A, Impurity-04 and Etoricoxib was found to be $3.09 \mathrm{~min}, 17.01 \mathrm{~min}$ and $21.45 \mathrm{~min}$ respectively with a run time of $45 \mathrm{~min}$.
\end{abstract}

Keyword: RP-HPLC, Etoricoxib, Method validation

\section{Introduction}

In this present study an attempt was made to develop RP-HPLC method and method validation of related substances in Etoricoxib in dosage form. The Etoricoxib (Figure 1) active ingredient is $\operatorname{arcoxia}^{1,2}$, etoricoxib is selective COX-2 inhibitor it inhibits the second isoform of cyclooxygenases enzyme (COX-2). Since COX-2 is crucial $^{3}$ in the production of prostaglandins, inhibition of COX-2 effectively decreases pain. Etoricoxib is indicated for the treatment of rheumatoid arthritis, Psoriatic arthritis, Osteoarthritis, ankylosing spondylitis, acute pain and gout. Its chemical formula is $\mathrm{C}_{18} \mathrm{H}_{15} \mathrm{ClN}_{2} \mathrm{O}_{2} \mathrm{~S}$ and molecular weight ${ }^{4}$ is $358.842 \mathrm{~g} / \mathrm{mol}$.<smiles>Cc1ccc(-c2ncc(Cl)cc2-c2ccc(S(C)(=O)=O)cc2)cn1</smiles>

Figure 1. Chemical structure of Etoricoxib

5-Chloro-6'-methyl-3-(4-(methylsulfonyl)phenyl)-2,3'-bipyridine 
HPLC method was developed for the determination of etoricoxib and the impurities arising during its manufacturing. In the present study, we describe a reverse phase liquid chromatography method for the separation of process and degradation impurities of etoricoxib. The developed method was validated for linearity, accuracy, precision, detection limit, quantification limit, robustness, specificity, and system suitability. Results of all validation parameters were within the limits as per ICH guidelines ${ }^{5,6}$.

\section{Experimental}

In this related substance of etoricoxib, there are two impurities (Figure 2) namely impurity- $04^{7}$ and impurity- $05 \mathrm{~A}^{8}$ were produced. All the reagents used were of analytical reagent grade. Milli Q water with TKAgen pure, methanol, acetonitrile and orthophosphoric acid of Merck and HPLC grade. Its chemical formulas are $\mathrm{C}_{15} \mathrm{H}_{15} \mathrm{NO}_{3} \mathrm{~S}$ and $\mathrm{C}_{7} \mathrm{H}_{14} \mathrm{ClF}_{6} \mathrm{~N}_{2} \mathrm{P}$. The molecular weights are $289.349 \mathrm{~g} / \mathrm{mol}$ and $306.62 \mathrm{~g} / \mathrm{mol}$.

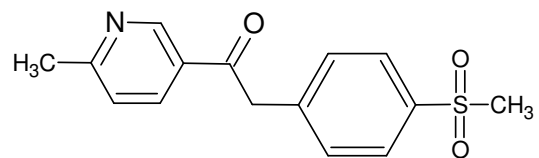

Impurity-04

1-(6-Methylpyridin-3-yl)-2-(4(methylsulfonyl)<smiles>CN(C)/C=C(Cl)/C=[N+](/C)C(F)(F)F</smiles>

Impurity-05A

2-Chloro-1,3-bis(dimethylamino)triethinium phenyl) ethanone) hexafluropho-sphate

Figure 2. Impurities of etoricoxib

\section{Chromatographic conditions}

Chromatographic separation was performed on Agilent HPLC, UV-detector with Inertsil ODS-3V $\mathrm{C}_{18}$ column $4.6 \times 250 \mathrm{~mm}$ (particle size with $5 \mu \mathrm{m}$ ) and constant flow rate. Rheodyne Injector with $10 \mu \mathrm{L}$ loop. The composition of mobile phase in the ratio $0.1 \mathrm{M}$ $\mathrm{KH}_{2} \mathrm{PO}_{4}$ buffer: Acetonitrile (80:10) was delivered at the flow rate $1.0 \mathrm{~mL} / \mathrm{min}$. The mobile phase was filtered through $0.45 \mu$ membrane filter and sonicated for $15 \mathrm{~min}$. It is performed with the UV-detector and wavelength observed is $238 \mathrm{~nm}$. It was performed in column temperature of $25^{\circ} \mathrm{C}$. Optimized chromatographic conditions are listed in Table 1.

Table 1. Optimized chromatographic conditions

\begin{tabular}{cll}
\hline S. No. & \multicolumn{1}{c}{ Parameter } & \multicolumn{1}{c}{ Condition } \\
\hline 1. & Mobile phase & $80 \% 0.1 \%$ OPA buffer : 20\% Acetonitrile \\
2. & Pump mode & Gradient \\
3. & Diluent & Buffer : Acetonitrile $(50: 50)$ \\
4. & Column & Inertsil ODS-3V, $(4.6 \times 250 \mathrm{~mm}, 5 \mu \mathrm{m})$ \\
5. & Wave length & $238 \mathrm{~nm}$ \\
6. & Column temperature & $25{ }^{\circ} \mathrm{C}$ \\
7. & Injection volume & $10 \mu \mathrm{L}$ \\
8. & Flow rate & $1.0 \mathrm{~mL} / \mathrm{min}$ \\
9. & Run time & $45 \mathrm{~min}$ \\
\hline
\end{tabular}

\section{Materials and Methods}

Distilled water (TKA gen pure), acetonitrile and methanol HPLC grade (Merck), potassium dihydrogen phosphate (Merck) were used as such. 


\section{Preparation of standard solution}

Accurately weighed $50 \mathrm{mg}$ of etoricoxib was transferred into a $50 \mathrm{~mL}$ of volumetric flask, about $25 \mathrm{~mL}$ of diluents was added, sonicated to dissolve and diluted up to the mark with diluent and then labelled as a standard.

\section{Preparation of sample solution}

Accurately weighed $50 \mathrm{mg}$ of etoricoxib sample was transferred into a $50 \mathrm{~mL}$ of volumetric flask, about $25 \mathrm{~mL}$ of diluents was added, sonicated to dissolve and diluted up to the mark with diluent and then labelled as a sample.

\section{Validation of Method}

\section{Specificity}

It is to demonstrate the absence of interferences between potential impurities of etoricoxib. The method will be selective if there is no interference of etoricoxib with its impurities such as impurity-04 and impurity-05A. To verify the specificity it is injected each single impurity standard solution, specificity solution, sample solution and a spiked sample solution. The results are observed in Table 2 .

Table 2. Specificity details

\begin{tabular}{llll}
\hline Name & RT, min & Relative RT & Resolution \\
\hline Related compound 05 A & 2.92 & 0.12 & 0.00 \\
Related compound 04 & 17.66 & 0.75 & 69.05 \\
Etoricoxib & 23.40 & 1.00 & 15.25 \\
\hline
\end{tabular}

\section{Precision}

Precision of an analytical method is the degree of agreement among individual test results when the method is applied repeatedly to multiple samplings of a homogenous sample. The precision of the related substance method was checked by injecting six individual preparations of etoricoxib. In this there are repeatability and Intermediate precision. Repeatability refers to the result of the method operating over a short time interval under the same condition. Intermediate precision refers to the results from within lab variation due to difference in experimental periods, analyst, and equipments. The precision was determined at the LOQ concentration for etoricoxib, Impurity-04 and impurity-05A and the \% RSD was found to be below 5\% for all impurities. The \% RSD of the area of each impurity was calculated.

\section{$\angle O D$ and $L O Q$}

The LOD and LOQ were determined by measuring the signal to noice ratio of the each substance. The LOD and LOQ for etoricoxib and its impurities such as impurity-04 and impurity-05A were determined by injecting a series of diluents solutions with known concentrations. Detection limit of a individual analytical procedure is the lowest amount of analyte in a sample which can be determined but not necessarily quantitated, under the stated experimental conditions. Quantitative limit of an individual analytical procedure is the lowest amount of analyte in a sample which can be quantitatively determined with suitable precision and accuracy. The values of LOD and LOQ for etoricoxib, and its impurities such as Impurity-04 and impurity-05A are mentioned in the Table 3. The \% RSD of the area of each impurity was calculated. 


\section{Accuracy}

The accuracy of an analytical method is the closeness of the test results obtained by that method to the true value.To evaluate the accuracy a sample is spiked with three different levels of Standard solution and three injections of each level are done. The accuracy of the method for all the related substances were determined by analysing Etoricoxib sample solutions spiked with all the related substances at different concentration levels of LOQ, 50, 100 and $150 \%$ of each at a specified limit. The accuracy of all related substances was found to be in between the predefined acceptance criteria.The percentage of recoveries for the impurities was calculated by injecting the standard solution for each level and the data was given in Table 3.

Table 3. Validation results summary of etoricoxib

\begin{tabular}{lllll}
\hline \multicolumn{1}{c}{ Parameter } & \multicolumn{1}{c}{ Etoricoxib } & & Impurity-04 & Impurity-05A \\
\hline $\mathrm{R}^{2}$ & 0.999 & 0.999 & 0.995 \\
Relative RT & 1.00 & 0.79 & 0.14 \\
Response factor & 0.30 & 0.45 & 0.45 \\
LOD in $\mu \mathrm{g} / \mathrm{mL}$ & -- & 0.00786 & 0.02900 \\
LOQ in $\mu \mathrm{g} / \mathrm{mL}$ & -- & 0.02013 & 0.18297 \\
$\%$ RSD at LOQ & 1.215 & 2.80 & 3.41 \\
System Precision & 0.91 & 0.67 & 1.43 \\
Method Precision & 0.39 & 0.20 & 1.52 \\
Accuracy at LOQ & -- & 108.4 & 104.4 \\
Accuracy at 100\% & -- & 93.1 & 101.1 \\
Accuracy at $150 \%$ & -- & 93.3 & 103.2 \\
$\%$ RSD of ruggedness & 7.11 & 1.32 & 1.62 \\
\hline
\end{tabular}

\section{Linearity}

The linearity study is performed with five levels; four levels of different concentrations are prepared and injected six replicates at each level. For the first one it can be used chromatograms obtained from quantification limit.The linearity of the method for all the related substances were determined by analysing etoricoxib sample solutions spiked with all the related substances at different concentration levels of $60,80,100$ and $120 \%$ of each at a specified limit. The correlation coefficient was calculated for each substance.

\section{Robustness}

It is an analytical procedure which measures its capacity to remain unaffected by small, nut deliberate variations in method parameters and provides an indication of its reliability during normal usage. To determine the robustness of the developed method, experimental conditions were deliberately altered and the resolution between the etoricoxib and its related substances such as impurity-04 and impurity-05A were recorded. The parameters selected were Sample stability, column temperature, flow rate, column and buffer.

\section{Ruggedness}

It is an analytical method in the degree of reproducibility of test results obtained by the analysis of the same samples under a variety of conditions, such as different laboratories, different analyst, different instruments, and different lots of reagent and in different days.To calculate intermediate precision it will be prepared a single level and will be done three injections by two different analysts on two different equipment and three different days. 


\section{Results and Discussions}

\section{Optimization of chromatographic conditions}

The main objective of the chromatographic method was to separate etoricoxib from impurity04 and impurity-05A. Different stationary phases such as $\mathrm{C}_{8}$ and $\mathrm{C}_{18}$ and as well as different mobile phases. During evaluation of different column chemistries, Inertsil column was observed to give better resolution with the buffer $\mathrm{pH}$ of 3.0. A good resolution and peak shape were optimized as mentioned under section "chromatographic conditions". In optimized chromatographic conditions etoricoxib, impurity-04, and impurity-05A were separated.

\section{Validation of the method}

\section{Forced degradation studies}

Degradation was not observed in etoricoxib sample when subjected to stress conditions like acid, base thermal and photolytic. Etoricoxib was spiked with all the impurities (Figure 3) and it was degraded under oxidation condition and very little in base and thermal conditions (Figure 4, 5 and 6). The summary of forced degradation study is mentioned in Table 4.

Table 4. Forced degradation study result of etoricoxib

\begin{tabular}{|c|c|c|}
\hline Stress condition & $\begin{array}{l}\% \text { Area of } \\
\text { Etoricoxib }\end{array}$ & $\begin{array}{l}\% \text { of Major } \\
\text { degradation }\end{array}$ \\
\hline Non-Stressed & 100 & 0.00 \\
\hline Acid Hydrolysis $\left(1 \mathrm{~N} \mathrm{HCl}, 80^{\circ} \mathrm{C}\right.$ for $3 \mathrm{~h}$ ) & 99.98 & 0.02 \\
\hline Base Hydrolysis $\left(1 \mathrm{~N} \mathrm{NaOH}, 80^{\circ} \mathrm{C}\right.$ for $\left.2 \mathrm{~h}\right)$ & 99.98 & 0.02 \\
\hline $\mathrm{H}_{2} \mathrm{O}_{2}$ Oxidation $\left(50 \% \mathrm{H}_{2} \mathrm{O}_{2}, 3 \mathrm{~h}\right.$ at $\left.80^{\circ} \mathrm{C}\right)$ & 99.53 & 0.47 \\
\hline Thermal degradation (Solid State, $80^{\circ} \mathrm{C}$ for 7 days) & 99.97 & 0.03 \\
\hline $\begin{array}{l}\text { Light Exposure; Solid State } \\
\text { (Solid sample, } 1.2 \text { million LUX Fluorescent Light } \\
\text { and } 200 \mathrm{~W} \bullet \mathrm{h} / \mathrm{m}^{2} \text { UV Fluorescent Light) }\end{array}$ & 99.99 & 0.01 \\
\hline
\end{tabular}

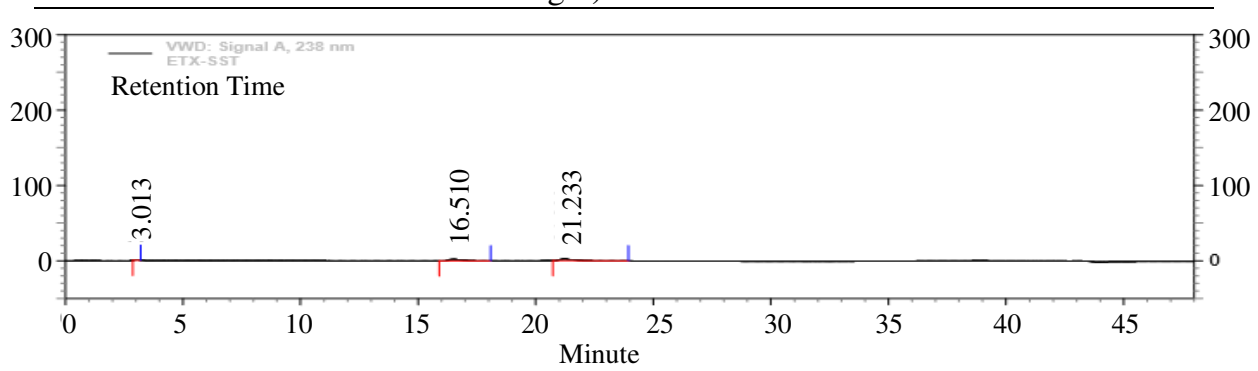

Figure 3. Etoricoxib spiked with all impurities

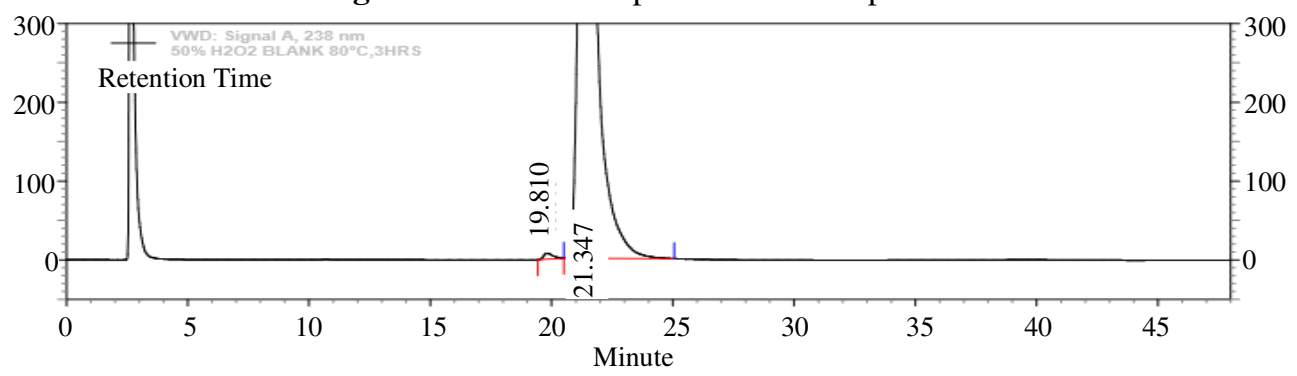

Figure 4. Etoricoxib peroxide degradation sample $50 \%$ Hydrogen peroxide $\left(3 \mathrm{~h}\right.$ at $\left.80{ }^{\circ} \mathrm{C}\right)$ 


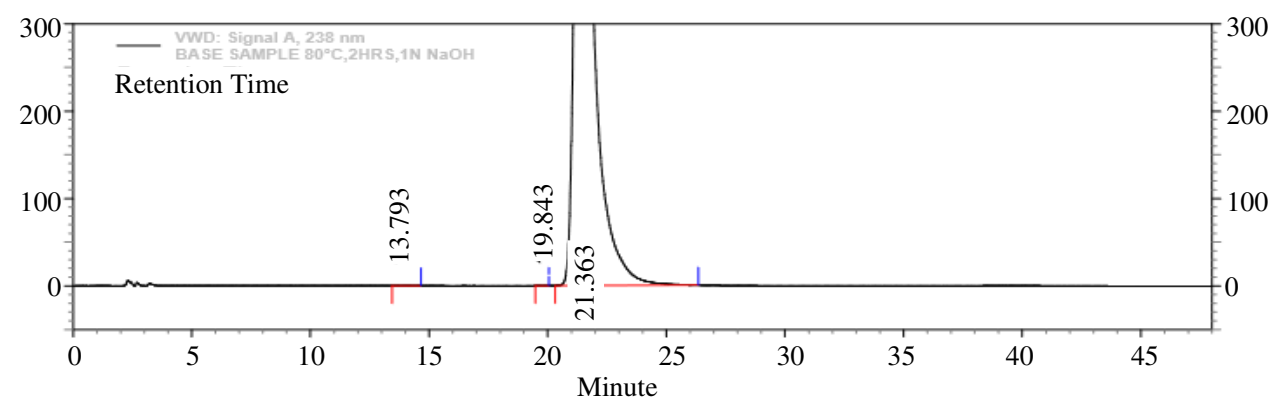

Figure 5. Etoricoxib base degradation $\left(1 \mathrm{~N} \mathrm{NaOH}, 80{ }^{\circ} \mathrm{C}\right.$ for $\left.2 \mathrm{~h}\right)$

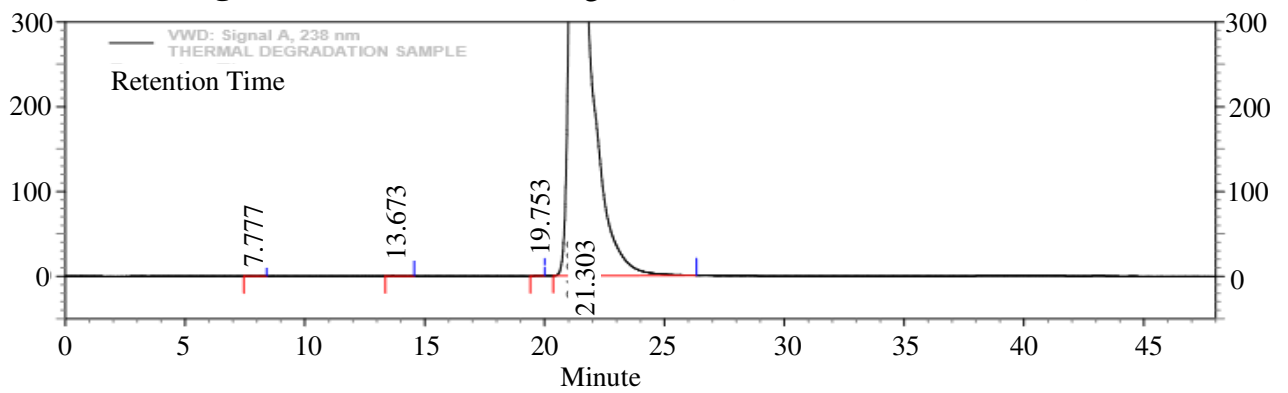

Figure 6. Etoricoxib thermal degradation (Solid state, $80{ }^{\circ} \mathrm{C}$ for 7 days)

\section{Solution stability}

There were no signification changes in the amounts of the impurities during solution stability experiment performed using the related substances method. The results from the studies indicated, the sample solution was stable in room temperature for $48 \mathrm{~h}$.

\section{Conclusion}

It is verified that the method for relative substance of etoricoxib is selective and has a good sensitivity. The method meets the requirements of linearity of the correlation coefficient (R), proportionality and slope tests, so it is linear in the range studied, it has a good precision (Instrumental repeatability and method reproducibility) and method accuracy also meets with the established criterion. The method was found to be simple, selective, precise, accurate and robust. Therefore, this method can be used for routine testing as well as stability analysis of etoricoxib drug substance. All statistical results were within the acceptance criteria.

\section{References}

1. Venugopal S, Tripathi U M and Devanna N, E-J Chem., 2011, 8(S1), S119-S126; DOI:10.1155/2011/726385

2. Daniel D S L, Richard F D O, Rejean F M N, Zhaoyin W P and Jacues Y G L, US Patent USP5816419, 1997.

3. Nageswara R, Rao S, Meena A and Raghuram R, J Pharma Biomed Anal., 2005, 39(3-4), 349-363; DOI:10.1016/j.jpba.2005.03.040

4. https://en.wikipedia.org/wiki/Etoricoxib.

5. International conferences of harmonization Q3A (R1). Draft revised guidance on impurities in new drug substances. 2006; Available from:http://www.ich.org 
6. International conferences of harmonization Q2 (R1). Validation of analytical procedures test and methodology. 2005; Available from:http://www.ich.org

7. http://coreyorganics.com/1-6-methylpyridin-3-yl-2-\%204-methylsulfonyl-phenylethanone.html

8. https://www.sigmaaldrich.com/catalog/product/aldrich/syx00031?lang=en\&region=IN 